\title{
Silenced bodies in academics' lives
}

Silenced bodies in academics' lives

\section{\#Counted Bodies, Bodies Counting}

I count. . .

The papers ongoing,

The number of points,

The teaching hours remaining,

But also the months,

Till the next evaluation.

Will I get this revision,

Or this acceptance,

Before they take a decision

About how much I count?

I run but count,

I sleep but count,

I eat but count,

I wake up and count,

I dance but count,

I play with my kids but count,

Insomnia and I count. . .

I'm too tired to count,

Tired of this coercion.

My whole body feels this contention,

Should I say "count tension"?

Paralysed it is,

Can I still breathe?

My body counts,

I count on my body,

I act upon it,

Dirty care I inflict on it

To go through this shit,

Will it?

Full of fury and tears,

Submerged by the fear,

Hold to my tenacity,

Gone my creativity...

Hoping this vulnerability,

My papers will go free.

I am trapped,

So far feels the time when,

With my kids I played,

On a stage I danced,

A meal I shared,

Without counting. . .

Accounting, Auditing \& 
AAAJ

34,8

\section{\#Losing Bodies, Lost Bodies}

Silent voices, invisible faces.

Another on-line session,

I shall prepare You for your evaluation.

Good morning, can You hear me?

Can You see me?

I try to reach You,

To humanise our accounting lectures,

But how can I succeed

With disembodied sessions?

You feel trapped at the age of twenty,

I feel shackled in my late thirties.

You have to keep up with your evaluations,

I have to mind my publications.

An e-mail from a student:

Madame, I feel anxious,

No strength for the final evaluation.

Take care, spring sessions are on their way.

Hope is on its way.

I think about You at times,

Wondering how You feel.

An e-mail comes in at night.

My body shivers,

My tears drop,

My children stop.

Mom, why are you so sad?

Hold my hand,

I lost a student,

I lost a student. .

I never saw Your face,

I never heard Your voice,

But I think about You,

Imagining Your face,

Imagining Your voice. . . 